\title{
Elevated Alpha Fetoprotein in Chronic HCV Liver Disease with and without Hepatocellular Carcinoma in Egyptian Patients
}

\author{
Waleed M.Serag \\ , Chemistry Department Faculty of Science-Suez University 2014
}

\begin{abstract}
This work to determine the relation of serum Alpha fetoprotein (AFP) elevated values and liver damage in chronic Hepatitis C Virus (HCV) infected patients with and without cirrhosis ( compensated and decompensated). A cross-sectional descriptive study was done at National liver institute in Egypt from the period of January 2014 till june 2014 Patients enrolled in study were known cases of chronic Hepatitis $C$ Virus liver disease and were complicated by development of cirrhosis and hepatocellular carcinoma . Demographic data such as age and gender were recorded. Detailed clinical history and examination were carried out and recorded. Complete blood count, liver function test, total protein, Albumin/Globulin $(A / G)$ ratio, serum Albumin, HBsAg, anti HCV, ultrasound whole abdomen and CT scan Abdomen. Alpha fetoprotein were investigated in ninety HCV infected patients classify into three group; group I without cirrhosis and without ascitis, group II with cirrhosis and with ascitis, group III Hepatocellular carcinoma with cirrhosis and with ascitis

Elevation level of alpha fetoprotein in all patients but in different degree .the mean in group $1(5.3 \mathrm{ng} / \mathrm{dl})$, in group $2(33.4 \mathrm{ng} / \mathrm{dl})$ and in group $3(457.4 \mathrm{ng} / \mathrm{dl})$ which is markedly elevated. There was a significant differencebetween serum alpha fetoprotein level in Hepatitis C Virus infected patients with and without cirrhosis and those with hepatocelleular carcinoma. The cut off level of $>400 \mathrm{ng} / \mathrm{dl}$ is considered to be the most sensitive level for detection of hepatocellular carcinoma (93.3\%)

This study suggests that serum alpha fetoprotein has significant association with liver damage. The level of alpha fetoprotein may serve as a useful sensitive marker for detection of hepatocellular carcinoma especially at level higher than $400 \mathrm{ng} / \mathrm{dl}$ and to differentiate between chronic HCV without cirrhosis and without ascitis and between $\mathrm{HCV}$ with cirrhosis and with ascitis. Alpha fetoprotein may serve as useful marker for follow up the progression of liver damage
\end{abstract}

Key words: Alpha Fetoprotein, chronic HCV, Hepatocellular carcinoma, Cirrhosis, Liver damage .

\section{Introduction}

Alpha-fetoprotein is a tumor marker that has been used for surveillance and diagnosis of hepatocellular carcinoma (HCC) in patients with cirrhosis. The prognostic capability of this marker in patients with HCC has not been clearly defined (1). Alpha fetoprotein is a specific glycoprotein. Elevated level of alpha fetoprotein is predicted in hepatocellular carcinoma but may be elevated in chronic HCV hepatitis without evidence of hepatocellular carcinoma. Such elevation can be explained due to hepatic inflammation and viral replication (2) . Hepatocellular carcinoma (HCC) develops during natural history of cirrhosis, the risk is higher in patients with viral hepatitis. HCC develops in one-third of cirrhotic during hepatitis. HCC develops in one-third of cirrhotic during their lifetime (3). The incidence of hepatocellular carcinoma (HCC) has rapidly increased in the last decade to reach the sixth most common cancers worldwide (4) .

The evolution of compensated and decompensated liver cirrhosis has been clearly defined in HCV infected patients (5) . The compensated disease often remains asymptomatic for many years, allowing a normal quality of life. The risk of decompensation is $18 \%$ and the survival probability is $91 \%$ at 5 years (6) and the percentage of decompensation and death at 1 and 2 years are $0 \%$. After a first decompensation, liver disease progresses more rapidly. The percentage of readmission for decompensation in HCV infected patients is $83 \%$ and the survival probability is $50 \%$ at 5 years (7). The purpose of the present study is to detect that in the egyptian patients, the elevation values of alpha fetoprotein are predicted not only in hepatocellular carcinoma but also in liver damage and to differentiate between chronic HCV with and without cirrhosis and with hepatocellular carcinoma . 


\section{Materials and methods}

A cross-sectional (descriptive) study was done at National liver institute in Egypt. Patients enrolled in study were known cases of chronic HCV liver disease and were complicated by development of cirrhosis and hepatocellular carcinoma . Demographic data such as age and gender were recorded. Detailed clinical history and examination were carried out and recorded . Complete blood count, liver function test, total protein, Albumin/Globulin (A/G) ratio, serum Albumin, $\mathrm{HBsAg}$, anti HCV, ultrasound whole abdomen and $\mathrm{CT}$ scan Abdomen. Alpha fetoprotein were investigated in ninety HCV infected patients classify into three group ; group I chronic HCV patients without cirrhosis and without ascitis, group II chronic HCV patients with cirrhosis and with ascitis with no evidence of hepatocellular carcinoma, group III chronic HCV patients with cirrhosis and with ascitis and with hepatocellular carcinoma . Alpha feto protein method by The electrochemiluminescence immunoassay"ECLIA"Cobas e 601 immunoassay analyzers. Cobas, Roche , US .

This work was carried out to investigate the relation between elevated level of alpha fetoprotein in various form of chronic $\mathrm{HCV}$ infected patients . Alpha fetoprotein was investigated in 90 patients with chronic HCV that were divided into three groups : Group I: chronic HCV patients without cirrhosis and without ascitis $(\mathrm{n}=30)$. Group II: chronic HCV patients with cirrhosis and with ascitis with no evidence of hepatocellular carcinoma $(n=30)$. Group III: chronic HCV patients with hepatocellular carcinoma with cirrhosis and with ascitis $(\mathrm{n}=30$. All patients were diagnosis by Ultrasound and CT by physicians to show the presence or absence of focal lesions in liver and ascites. All patients who positive for HBV infection were execluded from the study .

Ethical consideration:

Informed consent was taken from all participants. Each participant has the right to accept or refuse participation after explaining the objectives. Confidentiality of collected data was guaranteed to participants . The research have been approved by institutional review board Of national liver institute, Cairo.

\section{Results}

The current study shows the following results Table (1) shows the demographic characteristic in between the study groups as regard age (mean age was 49.2, 51.1, 52.2 year) and sex both 3 groups were matched together and the difference in between are statistically non significant $(p>0.05)$.Table (2) shows that alpha fetoprotein is higher in group 2 (HCV with liver cirrhosis and ascitis (mean 33,4) than non cirrhotic group (group 1) Mean (5.3) and markedly high (mean=457.4) among group 3 (HCV with cirrhosis and hepatocellular carcinoma) and the difference in between are statistically highly significant .Table (3) shows that sensitivity of the cut off level $>200 \mathrm{Ng} / \mathrm{dl}$ alpha fetoprotein $=20 / 30=66.6 \%$ The specificity of the cut off level $>200 \mathrm{ng} / \mathrm{dl}$ alpha fetoprotein $-56 / 60=93.3 \%$, while The sensitivity of the cut off level $>400 \mathrm{Ng} / \mathrm{dl}$ alpha fetoprotein $=28 / 30=93.3 \%$ and The specificity of the cut off level $>400 \mathrm{Ng} / \mathrm{dl}$ alpha fetoprotein $=59 / 30=98.3 \%$. 


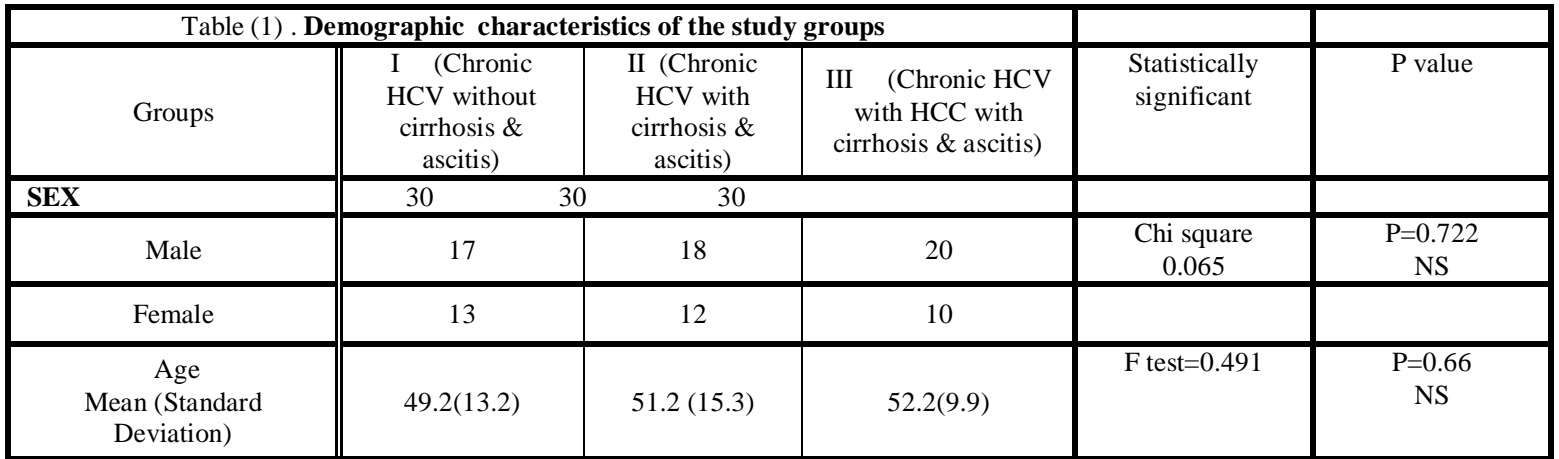

\begin{tabular}{|c|c|c|c|}
\hline \multicolumn{4}{|c|}{ Table (2) Data Evaluation of AFP values } \\
\hline & $\begin{array}{l}\text { I (Chronic } \\
\text { HCV without } \\
\text { cirrhosis \& } \\
\text { ascitis) }\end{array}$ & $\begin{array}{l}\text { II (Chronic } \\
\text { HCV with } \\
\text { cirrhosis \& } \\
\text { ascitis) }\end{array}$ & $\begin{array}{c}\text { III (Chronic HCV } \\
\text { with HCC with } \\
\text { cirrhosis \& ascitis) }\end{array}$ \\
\hline Alpha fetoprotein level & $\mathrm{N}=30$ & $\mathrm{~N}=30 \quad \mathrm{~N}=$ & \\
\hline Max & 22.1 & 155.8 & 2960 \\
\hline Min & 1.1 & 0.1 & 153.7 \\
\hline Mean & 5.3 & 33.4 & 457.4 \\
\hline $\begin{array}{c}\text { Standard } \\
\text { Deviation }\end{array}$ & 5.1 & 23.4 & 330.04 \\
\hline
\end{tabular}

\section{F test $-52.8 \quad P=0.000$ HS}

Table (3) Sensitivity and Specificity of AFP for detection of HCC

\begin{tabular}{|c||c|c|}
\hline Groups & $\begin{array}{c}\text { HCC } \\
\mathrm{N}=30\end{array}$ & $\begin{array}{c}\text { Non HCC } \\
\mathrm{N}=60\end{array}$ \\
\hline $\begin{array}{c}\text { Alpha fetoprotein }>200 \\
\mathrm{ng} / \mathrm{dl}\end{array}$ & Positive & Negative \\
\hline Positive & 20 & 4 \\
\hline Negative & 10 & 56 \\
\hline $\begin{array}{c}\text { Alpha fetoprotein }>400 \\
\text { ng/dl }\end{array}$ & Positive & Negative \\
\hline Positive & 28 & 1 \\
\hline Negative & 2 & 59 \\
\hline
\end{tabular}

\section{Discussion}

The HCV monoinfected patients with compensated liver cirrhosis do not seem to show evidence of rapidly progressive liver disease. Liver complications were the most frequent causes of death, representing $81 \%$ of the over all mortality . Every one of those who died had shown a decompensation during the follow up . Roughly half of the patients with decompensated cirrhosis at inclusion died within one year . A portosystemic encephalopathy was the most frequent cause of death (8). Patients with cirrhosis or chronic hepatitis due to either $\mathrm{HBV}$ or $\mathrm{HCV}$ require regular surveillance for $\mathrm{HCC}(\mathbf{9})$. Some studies have demonstrated that the presence of elevated levels of AFP in patients with LC (liver cirrhosis) is a risk factor for the development of HCC,$(\mathbf{1 0}, \mathbf{1 1})$ thus suggesting that increased AFP production in patients with LC might reflect, largely and abnormal or altered liver cell regeneration. Although serum AFP and ultrasongraphy every 6 to 12 months have been the preferred method of screening for many years, the optimal method and interval for surveillance are debated. $(\mathbf{1 0}, \mathbf{1 1}, \mathbf{1 2})$. Elevation of the AFP level was the way HCC was diagnosed prior to the availability of sensitive abdominal imaging techniques in the late 1970"s (13) . However, it soon became apparent with the advent of ultrasonography and CT scanning that many tumors could be detected in patients without an elevated AFP. The present study shows that alpha fetoprotein is markedly elevated in group with HCV with liver cirrhosis and hepatocellular carcinoma(HCC) than without HCC. AFP can be used as useful marker for detection and screening of HCC .In Accordance a study by (14) shows that Currently the recommended screening strategy for patients with cirrhosis includes the determination of serum AFP levels and an abdominal ultrasound every six 
months to detect $\mathrm{HCC}$ at an earlier stage .Another study by (15) concluded that AFP is a significant markers for Hepatocellular carcinoma, helpful in assessing problems in management of HCC and monitoring treatment regiments. In addition, AFP is also an indicator of HCC risks mostly in patients with cirrhosis and HCV/HBV infections. The current study shows that AFP level more than $200 \mathrm{ng} / \mathrm{dl}$ can detect $66.6 \%$ of $\mathrm{HCC}$ as sensitivity while by using AFP cut off level more than $400 \mathrm{ng} / \mathrm{dl}$ the sensitivity rises to 93.3\% A similar study by (16) which shows similar results as regard sensitivity og AFP higher than 200 $\mathrm{ng} / \mathrm{dl}$ was $70 \%$. The current study shows higher sensitivity of AFP in detecting HCC in level more than 400 $\mathrm{ng} / \mathrm{dl}$ and sensitivity was $93.3 \%$.In agreement with the current study, A study by( 17) which shows AFP cut off lecel from 400 to $500 \mathrm{ng} / \mathrm{dl}$ is highly diagnostic and address that The European Association for the Study of the Liver (EASL), for example, has listed standard criteria for diagnosis of HCC that incorporate both invasive and noninvasive measures. Noninvasive criteria include two imaging techniques, both demonstrating a focal lesion $>2 \mathrm{~cm}$ in diameter with features of arterial hypervascularization, or a single radiologic study with these features combined with a serum AFP level of $>400 \mathrm{ng} / \mathrm{ml}$

\section{Conclusion}

* The present study suggests that serum alpha fetoprotein has significant relation with liver damage in HCV infected patients with and without cirrhosis ( compensated and decompensated). AFP level may serve as a useful marker for detection of Hepatocellular carcinoma and to differentiate between chronic HCV with and without cirrhosis and a useful marker for follow up the liver damage.

\section{Acknowledgements}

I acknowledge Mr.Husien Mohamed engineer in Memphis pharmaceutical company for his work in design , analysis and interpretation of data .

I acknowledge all physicians in National liver institute for their help in samples collection.

Conflicts of interest : Non

\section{Reference}

[1]. Giannini EG, Marenco S, Borgonovo G, Savarino V, Farinati F, et al :

[2]. Alpha-fetoprotein has no prognostic role in small hepatocellular carcinoma identified during surveillance in compensated cirrhosis.Hepatology 56(4):1371-1379,2012.

[3]. Mallikarjun Patil , Keyur A and Sheth*, C : Elevated Alpha Fetoprotein, No Hepatocellular Carcinoma , J Clin Exp Hepatol ;1-3,2013.

[4]. Sangiovanni A, Prati GM, Fasani P, et al : The natural history of com-pensated cirrhosis due to hepatitis C virus: a 17-year cohort study of 214 patients. Hepatology. ;43:1303-1310,2006.

[5]. Llovet JM, Peña CE, Lathia CD, Shan M, Meinhardt G and Bruix J : Plasma biomarkers as predictors of outcome in patients with advanced hepatocellular carcinoma. Clin Cancer Res;18:2290-2300,2012

[6]. Benvegnu L, Gios M, Boccato S, and Alberth A :Natural history of compensated viral cirrhosis : a prospective study on the incidence and hierarchy of major complications. Gut 2004, 53:744-749,2004.

[7]. Planas R, Balleste B, Alvarez MA, et al ; Natural history of decompensated hepatitis C virus-related cirrhosis . A study of 200 patients . J Hepatol $2004 ; 40: 823-830,2014$.

[8]. Ragni MA,and Belle SH (2001: Impact of human immunodeficiency virus infection on progression to end stage liver disease in individuals with hemophilia and hepatitis c virus infection .J Infect Dis ; 183:1112-1115,2001.

[9]. Jose A Giron - Gonzalez, Francisco Brun, Alberto Terron, Antonio Vergara and Ana Arizcorreta .: Natural history of compensated and decompensated HCV related cirrhosis in HIV infected patients : a prospective multicentre study.

[10]. Antiviral Therapy $2007 ; 12: 899-907,2007$.

[11]. Bruix J and Sherman M : Practice Guideline. Committee American Association for the study of liver diseases. Management of hepatocellular carcinoma. Hepatology 42: 1208-36005; 42: 1208-1236 ,2005.

[12]. Rodriguez-Diaz JL, Rosas-Camargo V, Vega-Vega O, Morales- Espinosa D, Mendez-Reguera A, Martínez-Tlahuel JL, et al. : Clinical and pathological factors associated with the development of hepatocellular carcinoma in patients with epatitis virusrelated cirrhosis: a long-term follow-up study. Clin Oncol (R Coll Radiol) ; 19: 197-203,2007.

[13]. Arrieta O, Rodríguez-Díaz J, Rosas-Camargo V, Morales-Espinosa D, Ponce de León S, Kershenobich D, et al. : Colchicine delays the development of hepatocellular carcinoma in patients with hepatitis virus related-liver cirrhosis.Cancer 2006;107:1852-1858,2006.

[14]. Di Bisceglie AM .: Issues in screening and surveillance for hepatocellular carcinoma. Gastroenterology 2004; 127: S104107,2004 .

[15]. Sherman M: Alpha fetoprotein: an obituary. J Hepatol ; 34: 603-605,2001

[16]. Bertino G , Bruno S , Calvagno AM, Malaguarnera M et al : Diagnostic and prognostic value of alpha-fetoprotein, des- $\gamma$ carboxy prothrombin and squamous cell carcinoma antigen immunoglobulin M complexes in hepatocellular carcino. Minerva Med. Oct;102(5):363-371,2011.

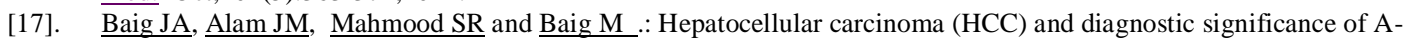
fetoprotein (AFP). J Ayub Med Coll Abbottabad.Jan-Mar;21(1):72-75,2009.

[18]. Kazuhisa Ta, Shigeru Ok,and Ne Win : Evaluation ofTumor Markers for the Detection ofHepatocellular Carcinoma in Yangon General Hospital, Myanmar

[19]. Acta Med. Okayama, Vol. 56, No. 6, pp. 317-320,2002.

[20]. 17) Eldad S. Bialecki and Adrian M : Diagnosis of hepatocellular carcinonoma HPB (Oxford). 2005; 7(1): 26-34,2005. 